\title{
QUANTIFICATION OF ANGIOGENESIS ON THE RAT AORTIC RING ASSAY
}

\author{
Silvia Blacher, Laetitia DeVy, Agnes NoEl AND JeAn-Michel FoidART \\ Laboratory of Tumor and Developmental Biology, University of Liège, Tour de Pathologie (B23), Sart-Tilman; \\ B-4000 Liège \\ e-mail: silvia.blacher@ulg.ac.be \\ (Accepted January 31, 2003)
}

\begin{abstract}
Image analysis is used to quantify angiogenesis on the rat aortic ring model. This technique allows to determine: (1) the aortic ring area and factor shape; (2) the number of microvessels, the total number of branching, the maximal microvessel length and the number of microvessels in function of the distance to the aortic ring; (3) the total number of isolated fibroblast-like cells and the number of fibroblast-like cells in function of the distance to the aortic ring. We show that this method is suitable to quantify spontaneous angiogenesis as well as to analyse a complex microvascular network induced by vascular endothelial growth factor (VEGF).
\end{abstract}

Keywords: angiogenesis, complexity, fibroblast-like cells, microvessels, quantification.

\section{INTRODUCTION}

In vitro angiogenesis assays are important for identification of potential angiogenic agents and screening for pharmacological inhibitors. Among these assays, the rat aortic ring model (Nicosia and Ottinetti, 1990) bridges the gap between in vivo and in vitro models. On this system, rat aortic rings cultured in collagen gel give rise to microvascular networks composed of branching endothelial channels. By using intact vascular explants, it reproduces more accurately the environment in which angiogenesis takes place than those with isolated endothelial cells. The quantification of angiogenesis on this system implies the determination of: (i) the number and length of branching microvessels; (ii) the size and form of aortic rings and (iii) the number and spatial distribution of fibroblast-like cells. To our knowledge, quantification on the aortic ring model has been performed according to the three following approaches: (i) manual processing and measurement (Kobayashi et al., 1998; Brown et al., 1996); (ii) global characterisation (Bocci et al., 1999; Kruger et $a l ., 2000)$ and (iii) automatic binary processing of grey level image and determination of the number and the total area of microvessels at a fixed distance from the aortic ring (Nissanov et al., 1995). Those kinds of quantification suffer from a number of practical difficulties. Mainly manual processing is slow, annoying and subjective. Nissanov et al. (1995) approach present the great advantages of being fully automatic. Nevertheless, as noticed by the authors themselves, the vessel area determination, cannot allow to distinguish between increased vessel length and increased vessel number. The aim of the present study is to develop an image-processing method, which allows to extract vessels and fibroblast-like cells during spontaneous or modulated angiogenesis and to determine additional relevant parameters.

\section{MATERIALS AND METHODS}

Angiogenesis was studied by culturing aortic explants in three-dimensional matrix gels according to the procedure of Nicosia and Ottinetti (1990). Thoracic aortas were removed from 8- to 12- weekold male fisher-344 rats and immediately transferred to a culture dish containing cold serum-free Minimum Essential Medium (MEM, Life Technologies Ltd., Paisley, Scotland). The periaortic fibroadipose tissue was carefully removed with fine microdissecting forceps and iridectomy scissors, paying special attention not to damage the aortic wall. $1 \mathrm{~mm}$-long aortic rings (approximately 20 per aorta) were sectioned and extensively rinsed in 5 consecutive washes of MEM medium. Ring-shaped explants of rat aorta were then embedded in gels of rat tail interstitial collagen $(1.5 \mathrm{mg} / \mathrm{ml})$ as previously described (Montesano at al., 1983). The final collagen solution was obtained by mixing 7.5 volumes of collagen $(2 \mathrm{mg} / \mathrm{ml})$ (Collagen R, Serva, Heidelberg, Germany) with 1 volume of 
$10 \times$ MEM, 1.5 volumes of $\mathrm{NaHCO}_{3}(15.6 \mathrm{mg} / \mathrm{ml})$ and approximately 0.1 volume $\mathrm{NaOH}(1 \mathrm{M})$ to adjust the $\mathrm{pH}$ to 7.4. The collagen gel cultures were first prepared in cylindrical agarose wells (Nicosia and Ottinetti, 1990) and kept in triplicates at $37^{\circ} \mathrm{C}$ in $100 \mathrm{~mm}$ diameter Petri dishes (bacteriological polystyrene, Falcon, Becton Dickinson, Lincoln Park, New Jersey). The identification of endothelial cells was based on their ability to uptake low-density lipoprotein (LDL). Prior to sectioning and collagen embedding, aortas were incubated for 4 hours at $37^{\circ} \mathrm{C}$ in a solution of $10 \mu \mathrm{g} / \mathrm{ml}$ acetylated-LDL labelled with the fluorescent probe $1,1^{\prime}$ dioctadecyl-3, 3,3', 3'-tetramethyl-indocarbocyanine perchlorate (Dil-Ac-LDL) (Biomedical Technologies Inc., Stoughton, Massachussets) (Voyta at al., 1984). Cultures were then examined by fluorescent microscopy using rhodamine excitation and emission filters. Aortic ring and microvascular endothelial cells were fluorescent whereas the intensity of fibroblast-like cells (smooth muscle cells and pericytes) was only slightly above background levels.

The aortic outgrowth was evaluated in the presence of vascular endothelial growth factor (VEGF, Sigma) added to the culture medium $(5-20 \mathrm{ng} / \mathrm{ml})$ immediately after aortic ring embedding. The cultures were kept at $37^{\circ} \mathrm{C}$ in a humidified environment for two weeks and examined every second day by phase contrast microscopy with an Olympus microscope. Image analysis was performed on a WorkStation Sun SPARC30, using the software 'Visilog5.0' from Noesis. Images were digitised in $760 \times 540$ with 256 grey levels. Grey level image transformation and binary image processing have been carrying out using traditional tools and mathematical morphology (Coster and Chermant, 1985). Testing was conducted by using at least triplicate culture per condition.

\section{RESULTS}

Fig. 1a shows a typical image of an aortic ring at day 10 of culture, giving rise to branching microvessels, surrounded by elongated fibroblast-like isolated cells. Binary images have been performed by the two-step procedure i.e., aortic ring extraction on the one hand, and microvessels and fibroblast-like cells extraction on the other hand. For the aortic ring extraction, a closing transformation was applied to smooth the background and eliminate microvessels and fibroblast-like cells (Fig. 1b). Then, the image was binarized using the threshold which maximizes the interclass variance of the grey levels (Otsu, 1979) (Fig. 1c). To extract microvessel and fibroblast-like cells the following steps were performed: the closed image (Fig. 1b) was subtracted from the original image (Fig. 1a) and the resulting image was binarized using the Otsu method (Otsu, 1979). Fig. 1e shows the resulting image after the elimination of artefacts located at the border of the image. An opening transformation was then used to filter fibroblast-like cells (Fig. 1g). Using this last image as a marker, the microvessel image is obtained by a reconstruction operation (Fig. 1f). Finally, the fibroblast-like cells image (Fig. 1g) results from the difference between the total binary image (Fig. 1e) and the image of microvessels (Fig. 1h).

After the generation of binary images, the aortic ring area $(\mathrm{A})$ and the shape factor $(\mathrm{F})$ defined as $\mathrm{F}=$ perimeter ${ }^{2} / 4 \pi$ A (Serra, 1982) have been measured. The microvessels and fibroblast-like cells were then quantitatively studied, depending on the vascular network complexity ( $\mathrm{a}$, and $\mathrm{b}$ below) acknowledged in this work:

a) Spontaneous angiogenesis (e.g., Fig. 1a, 2a). In this case, aortic outgrowth is evaluated without adding any exogenous factor. Each microvessel with its branching can be clearly identified. The number of microvessels $\left(\mathrm{N}_{\mathrm{v}}\right)$, their maximal length $\left(\mathrm{L}_{\max }\right)$, and the total number of branching $\left(\mathrm{N}_{\mathrm{b}}\right)$ have been measured. To achieve this goal, the number of intersections $\left(\mathrm{N}_{\mathrm{i}}\right)$ of microvessels with a grid defined as the successive boundaries of the aortic ring $n$-dilate $(\mathrm{n}=1,2,3 \ldots)$ was considered (Fig. 1h). In this construction, allowing to take into account the particular geometry of the studied aortic ring, increasing boundaries correspond to increasing distances $\mathrm{D}$ to the aortic ring. The $\mathrm{N}_{\mathrm{i}}$ value at a fixed arbitrarily distance $\mathrm{D}=0.01 \mathrm{~mm}$, gives $\mathrm{N}_{\mathrm{v}}$. The grid level $\mathrm{D}$ at which the last $\mathrm{Ni} \neq 0$ is measured, gives $\mathrm{L}_{\max }$. The sum of additional intersections detected at each level of the grid gives $\mathrm{N}_{\mathrm{b}}$. The number of intersections of microvessels $\left(\mathrm{N}_{\mathrm{i}}\right)$ at each level D of the grid (see Fig. 1h), defines the function $\mathrm{Ni}(\mathrm{D})$. This function, conveniently normalized, is the probability density function of the distance at which microvessels and/or branching exist. Finally, the number of fibroblastlike cells placed into the successive enlargement of the aortic ring limits (Fig. 1i) defines the probability density function $\mathrm{N}_{\mathrm{f}}(\mathrm{D})$ of the distance at which fibroblast-like cells can be observed.

To describe the $\mathrm{N}_{\mathrm{i}}(\mathrm{D})$ and $\mathrm{N}_{\mathrm{f}}(\mathrm{D})$ functions, the following statistical parameters have been calculated (Himmelblau, 1970): (i) the mean distribution $\overline{\mathrm{D}}$ and the standard deviation; (ii) the 
mode (most probable value of d) (d); (iii) the skewness (sk), which describes the symmetry of the distribution $(\mathrm{sk}=0$ for symmetrical distributions, sk $<0$ or sk $>0$ for nonsymmetrical distributions with the longer "tail" of the curve to the left or to the right, respectively) and (iv) the kurtosis (k) which describes how flat or peaked the distribution is $(\mathrm{k}=0$ for a gaussian distribution, $\mathrm{k}<0$ for a flat distribution and $\mathrm{k}>0$ for a peaked one). In our study, $\overline{\mathrm{D}}$ corresponds to the distance from the explant at which $\mathrm{N}_{\mathrm{i}}$ or $\mathrm{N}_{\mathrm{f}}$ reach its mean value, $d$ corresponds to the distance from the explant at which most cells migrated, a positive sk value indicates that most cells migrate at distances lower than $\overline{\mathrm{D}}$ and $\mathrm{k}$ indicates the cell dispersion around $\mathrm{d}$.

b) Induced-angiogenesis (e.g., Fig. 3a). In this case, microvessel outgrowth is evaluated after addition of a well-known pro-angiogenic molecule (VEGF). Each microvessel displayed a large number of branchings elongated in all directions. Consequently, the microvascular network formed a complex interconnected structure, in which the measurement of $\mathrm{N}_{\mathrm{v}}, \mathrm{N}_{\mathrm{b}}$ and $\mathrm{L}_{\max }$ were meaningless. Accordingly, only $\mathrm{N}_{\mathrm{i}}(\mathrm{D})$ has been determined.

Angiogenic parameters were automatically evaluated on rat aortic rings after 8 of culture in the following situations: (i) a spontaneous angiogenic response and (ii) a VEGF-induced angiogenesis. From Table 1, it must be noticed that the area A and the shape factor $F$ had almost the same value for each set of experiment. This allows to assert that results did not depend on the particular size or geometry of the aortic rings.

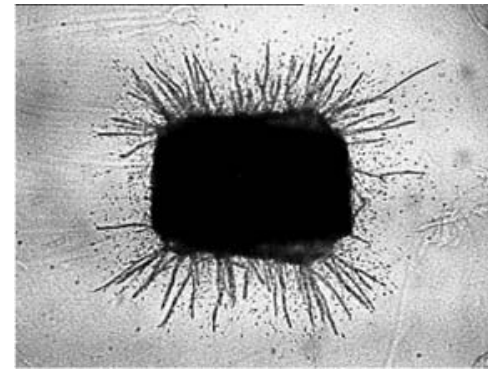

a)

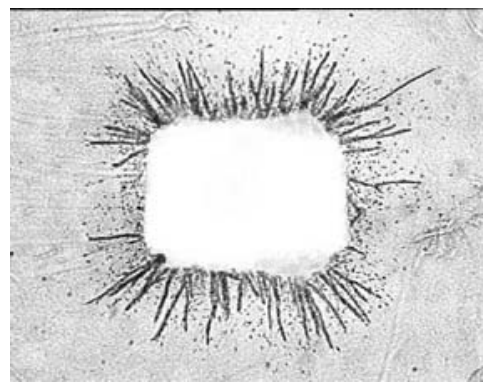

d)

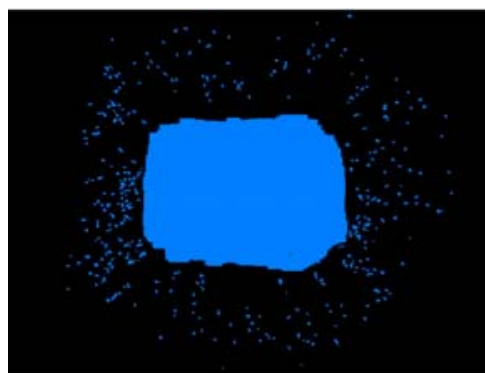

g)

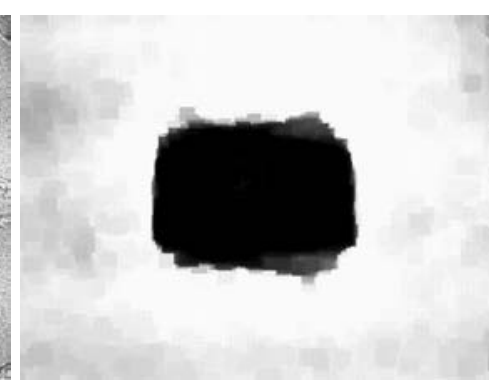

b)

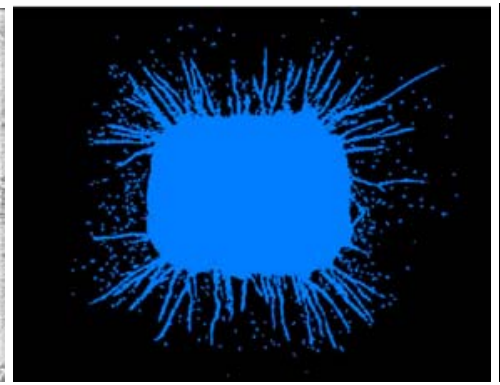

e)

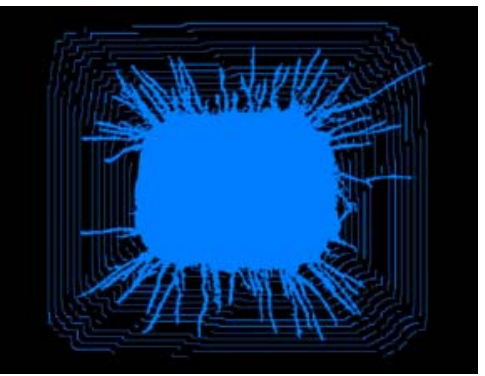

h)

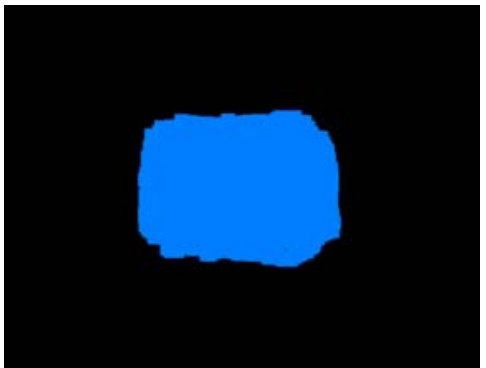

c)

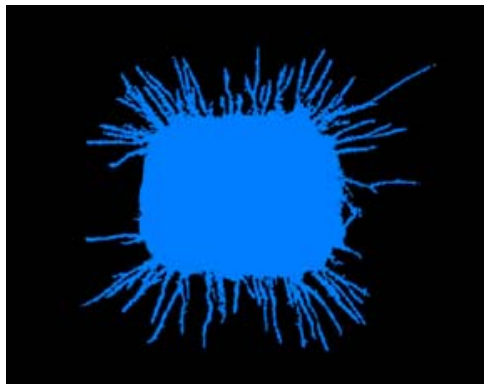

f)

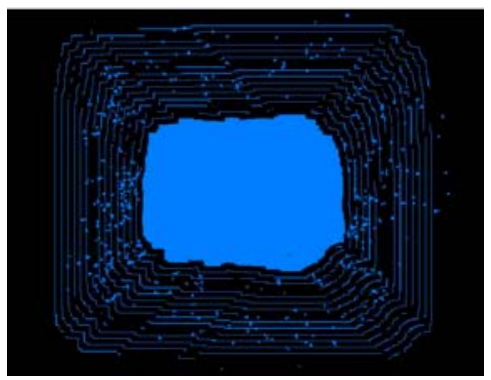

i)

Fig. 1. a)-g) Binary image processing of a typical aortic ring with endothelial cells organised as branching microvessels surrounded by isolated fibroblast-like cells. Angiogenesis quantification: h) determination of the microvascular outgrowth and i) fibroblast migration. 
After 8 days of culture, aortic explants embedded in collagen gels gave rise to capillary-like structures with isolated fibroblast-like cells, primarily confined in periaortic location (Fig. 2a). In this case, all the parameters linked to endothelial sprouting $\left(\mathrm{N}_{\mathrm{v}}, \mathrm{N}_{\mathrm{b}}\right.$, $\mathrm{L}_{\max }$ ), and fibroblast-like cells $\left(\mathrm{N}_{\mathrm{f}}\right)$ can be clearly determined (Table 1).

The complexity of the vascular network and fibroblast migration is quantified by the analysis of the $\mathrm{N}_{\mathrm{i}}(\mathrm{D})$ and $\mathrm{N}_{\mathrm{f}}(\mathrm{D})$ functions. $\mathrm{N}_{\mathrm{i}}(\mathrm{D})$ has a peak $(\mathrm{k}<0)$ nearby the aortic ring $(\mathrm{d}=0.23 \mathrm{~mm})$ and then decreases $(\mathrm{sk}=0.23)$ (Fig. 2b). This indicates that the structure was rather ordered, i.e., microvessels were short and had few branching. Compared to the $\mathrm{N}_{\mathrm{i}}(\mathrm{D})$ function, the $\mathrm{N}_{\mathrm{f}}(\mathrm{D})$ is shifted, has a rather flat peak $(\mathrm{k}>0)$ centred at $\mathrm{d}=0.17 \mathrm{~mm}$, and then decreases less steeply than $\mathrm{N}_{\mathrm{i}}(\mathrm{D})(\mathrm{sk}=0.51) . \mathrm{N}_{\mathrm{f}}(\mathrm{D})$ reached its smallest values at distances corresponding approximately to $\mathrm{L}_{\max }$ (Fig. 2c and Table 1).

In order to apply our quantification method to induced angiogenesis, rat aortic rings were cultured in the presence of VEGF164 $(20 \mathrm{ng} / \mathrm{nl})$, a key regulator of angiogenesis (Fig. 3a). In this case, a notable increase of network complexity was observed. As shown in Fig. 3a the interconnected microvessels prevented to determine accurately $\mathrm{L}_{\max }$. Nevertheless, a qualitative value of $1.3 \mathrm{~mm}$ corresponding to the distance at which the last intersection was observed has been measured. A comparison between Figs. 2b and $3 b$ show that the $\mathrm{N}_{\mathrm{i}}(\mathrm{D})$ function corresponding to the stimulated sample is shifted, extends towards the long distances, and is more peaked (increased values of D, sk, k, and ( D -d)), compared to the noninduced cultures (spontaneous angiogenesis).

Indeed, $\mathrm{N}_{\mathrm{i}}(\mathrm{D})$ increases at short distances from the aortic ring (in the range $0-0.26 \mathrm{~mm}$ ), reaches a maximum $(\mathrm{d}=0.26 \mathrm{~mm})$ and then decreases slowly at longer distances (in the range 0.5-1.4 mm). This shape is the signature of an interconnected network. Consequently, higher the broadness of the maximum, higher the network complexity is.

Indeed, $\mathrm{N}_{\mathrm{i}}(\mathrm{D})$ increases at short distances from the aortic ring (in the range $0-0.26 \mathrm{~mm}$ ), reaches a maximum $(\mathrm{d}=0.26 \mathrm{~mm})$ and then decreases slowly at longer distances (in the range 0.5-1.4 mm). This shape is the signature of an interconnected network. Consequently, broader is the maximum, more complex the network is.

\section{DISCUSSION}

This method allows to quantify number, branching, length, and the outgrowth of microvessels. Moreover, the shape of $\mathrm{N}_{\mathrm{i}}$ (D) appears as an indicator of the degree of complexity of the vascular network. When microvessels grow radially, as in the spontaneous angiogenic response, $\mathrm{N}_{\mathrm{i}}(\mathrm{D})$ displays a peak which is close to the aortic ring and decreases monotonically. On the contrary, when a branched structure is observed, as after VEGF-stimulation of angiogenesis, $\mathrm{N}_{\mathrm{i}}$ (D) has a peak at longer distance from the explant. In this situation, maximal $\mathrm{N}_{\mathrm{i}}$ value corresponds to maximal network density. Consequently, the broader the peak is, the more complex the structure of intertwined branching should be expected. It must be noticed that this method is valuable on a microscopic level at which both the explant and the microvessels structure are observed. At the vascular level, at which only a portion of the structure is observed, microvessels and fibroblast cannot be determined. The present work demonstrates that the particularities of each $\mathrm{N}_{\mathrm{i}}$ (D) function can be described by statistical parameters that allow comparing various experimental situations, and characterise the network complexity. The advantage of this technique is that it allows the quantification and positioning of fibroblast-like cells.

Table 1. Image analysis quantification of angiogenesis in the rat aortic assay.

\begin{tabular}{l|l|l|l|l|l|l|l}
\hline $\begin{array}{l}\text { Days } \\
\text { of culture }\end{array}$ & $\begin{array}{l}\text { Culture } \\
\text { conditions }\end{array}$ & $\begin{array}{l}\mathrm{A} \\
\left(\mathrm{mm}^{2}\right)\end{array}$ & $\mathrm{F}$ & $\mathrm{N}_{\mathrm{v}}$ & $\mathrm{N}_{\mathrm{b}}$ & $\mathrm{N}_{\mathrm{f}}$ & $\begin{array}{l}\mathrm{L}_{\max } \\
(\mathrm{mm})\end{array}$ \\
\hline 8 & $\begin{array}{l}\text { Spontaneous } \\
\text { Response }\end{array}$ & $2.64 \pm 0.2$ & $1.49 \pm 0.20$ & $38 \pm 3$ & $23 \pm 5$ & $416 \pm 20$ & $0.74 \pm 0.20$ \\
\hline 8 & VEGF & $2.65 \pm 0.1$ & $1.71 \pm 0.30$ & - & - & - & - \\
\hline
\end{tabular}




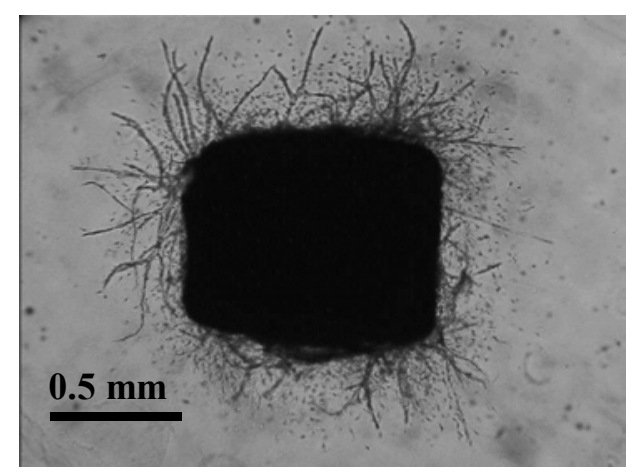

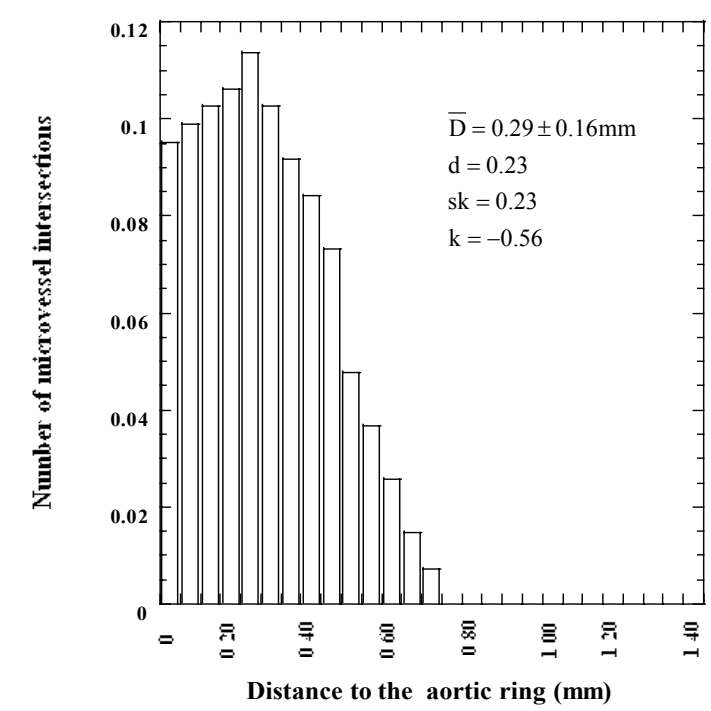

b)

a)

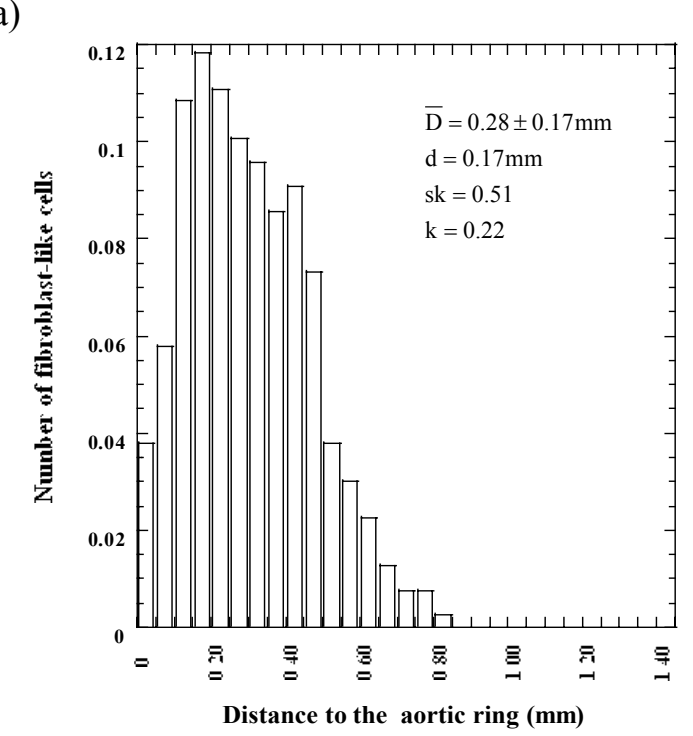

c)

Fig. 2. a) Spontaneous angiogenesis. b) the number of microvessel intersections in function of the distance to the aortic ring $(\mathrm{Ni}(\mathrm{D}))$, c) the number of fibroblast-like cells in function of the distance to the aortic ring $(N f(D))$.

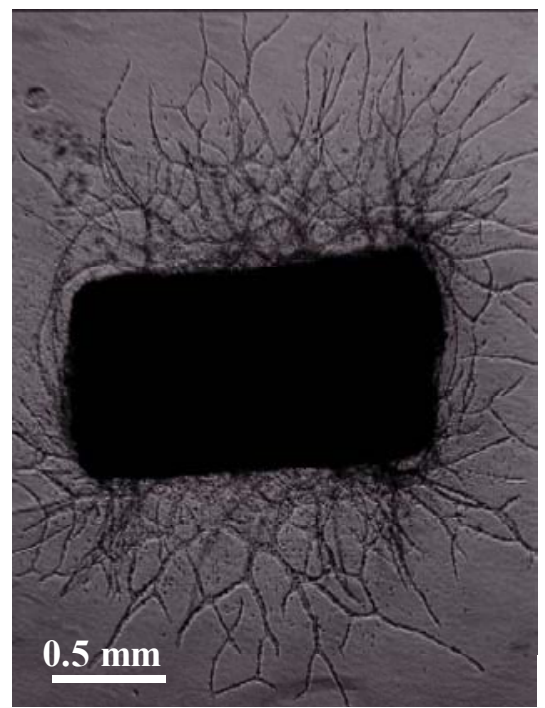

a)

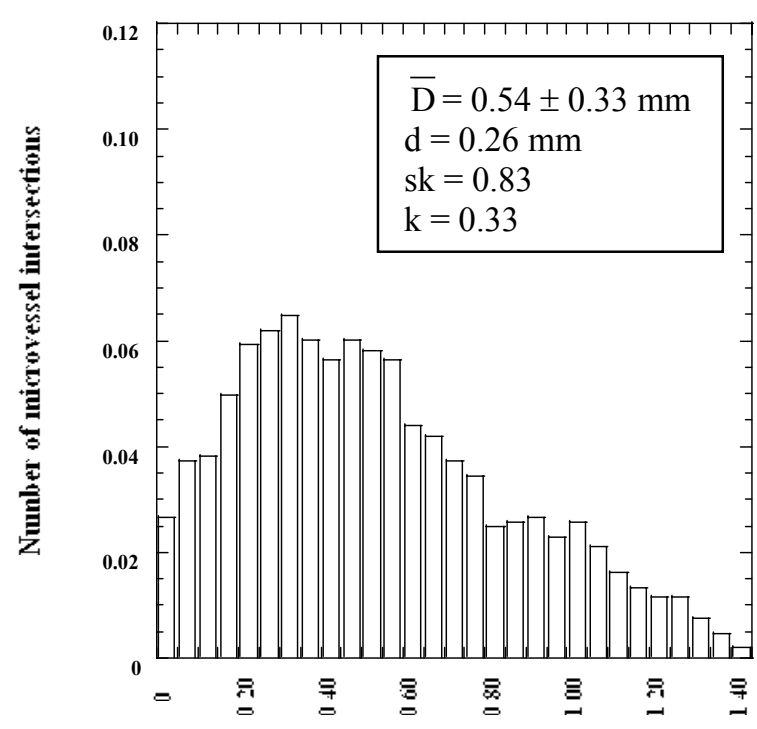

b) Distance to the aortic ring $(\mathbf{m m})$

Fig. 3. a) VEGF-induced angiogenesis, $b) N_{i}(D)$ in the VEGF-treated cultures. 


\section{REFERENCES}

Bocci G, Danesi R, Benelli U, Innocenti F, Di Paolo A, Fogli S, Del Tacca M (1999). Inhibitory effect of suramin in rat models of angiogenesis in vitro and in vivo. Cancer Chemother Pharmacol. 43:205-12.

Brown KJ, Maynes SF, Bezos A, Maguire DJ, Ford MD, Parish CR (1996). A novel in vitro assay for human angiogenesis. Lab Invest 75:539-55.

Coster M, Chermant JL (1985). Précis d'analyse d'images. Paris: CNRS.

Himmelblau DM (1970). Process Analysis by statistical methods. New York: Wiley.

Kobayashi S, Fukuta M, Kontani H, Yanagita S, Kimura I (1998). A quantitative assay for angiogenesis of cultured choroidal tissues in streptozotocin-diabetic wistar and spontaneously diabetic GK rats. Jpn J Pharmacol 78:471-8.

Kruger EA, Duray PH, Tkosos MG, Venzon DJ, Libutti SK, Dixon SC, Rudek MA, Pluda J, Allegra C, Figg W (2000). Endostatic inhibits microvessel formation in the ex vivo rat aortic ring angiogenesis assay. Biochem Biophys Res Commun 268:183-91.

Montesano R, Orci L, Vassali P (1983). In vitro rapid organisation of endothelial cells into capillary-like networks is promoted by collagen matrices. J Cell Biol 97:1648-52.

Nicosia RF, Ottinetti AA (1990). Growth of microvessels in serum-free matrix culture of rat aorta: a quantitative assay of angiogenesis in vitro. Lab Invest 63:115-22.

Nissanov J, Tuman RW, Gruver LM, Fortunato JM (1995). Automatic vessel segmentation and quantification of the rat aortic ring assay of angiogenesis. Lab Invest 73:734-9.

Otsu N (1979). A threshold selection methods from graylevel histograms. IEEE Trans Syst Man Cybern 9:62.

Serra J (1982). Image analysis and mathematical morphology. Vol. 1. Academic press, Inc.

Voyta JC, Via DP, Butterfield CE, Zetter BR (1984). Identification and isolation of endothelial cells based on their increased uptake of acetylated-low density lipoprotein. J Cell Biol 99:2034-40. 